\title{
Medical Audit of Documentation of Inpatient Medical Record in a Multispecialty Hospital in India
}

\author{
${ }^{1}$ Madhav M Singh, ${ }^{2}$ Saroj Patnaik, ${ }^{3}$ Bhandaru Sridhar
}

\begin{abstract}
Introduction: A medical record enables healthcare professionals to plan and evaluate a patient's treatment and ensures continuity of care among multiple providers. A study was conducted to do medical audit of documentation of inpatient medical record in a multispecialty hospital to assess whether the existing documentation procedure is as per laid-down policy.
\end{abstract}

Study design: Retrospective, descriptive study.

Study area: A 545 bed multispecialty hospital in medical ward, gynecology and obstetrics ward, surgical ward, ear, nose, and throat (ENT) ward, eye ward, pediatric ward, skin ward, and psychiatry ward.

Sample size: Systematic random sample of all inpatient medical records of select ward of last 12 months was done. Sample size was 320 case sheets, 40 from each department. The data collected were primary and the source was the discharge case files of the last 12 months available in the medical record section. The approach used for data collection was quantitative. The techniques applied were survey and observation. A structured checklist (audit tool) with 26 checklist points was developed keeping few of the quality indicators as the benchmark.

Findings: Gynecology and pediatric department records were not found appropriate. Psychiatry and dermatology dept record keeping was found appropriate as per laid-down policy. Planned care was not planned as per standard protocol in surgery department.

Recommendation: Sensitizing the clinical staff regarding the importance of proper documentation of the forms and hospital-wide standardization of the medical record keeping including admission and discharge summary. Rewarding the best performing department/unit and educating and training the responsible staff to make a complete record of every patient should be emphasized in the hospital. There should be monthly audit of the documentation procedure.

Conclusion: Medical records are technically valid health records that must provide an overall correct description of each patient's details of care or contact with hospital personnel. Medical records form a very important and critical document in hospital. These records are vital for legal purposes and for future planning of the hospital medical care.

\footnotetext{
${ }^{1}$ Assistant Registrar, ${ }^{2} \mathrm{MO}(\mathrm{HS}),{ }^{3} \mathrm{DDG}(\mathrm{HR})$

${ }^{1}$ Military Hospital, Meerut, Uttar Pradesh, India

${ }^{2}$ OIC Pay cell, O/O DGAFMS, New Delhi, India

${ }^{3} \mathrm{O} / \mathrm{O}$ DGAFMS, New Delhi, India
}

Corresponding Author: Saroj Patnaik, MO (HS), OIC Pay cell O/O DGAFMS, New Delhi, India, e-mail: patnaik.saroj@gmail.com
Keywords: Checklist, Documentation, Inpatient medical record, Medical audit.

How to cite this article: Singh MM, Patnaik S, Sridhar B. Medical Audit of Documentation of Inpatient Medical Record in a Multispecialty Hospital in India. Int J Res Foundation Hosp Healthc Adm 2017;5(2):77-83.

Source of support: Nil

Conflict of interest: None

\section{INTRODUCTION}

A medical record enables healthcare professionals to plan and evaluate a patient's treatment and ensures continuity of care among multiple providers. ${ }^{1}$ The quality of care a patient receives depends directly on the accuracy and legibility of the information the medical record contains. ${ }^{2}$ Maintaining a complete record is important not only to comply with licensing and accreditation requirements, but also to enable a healthcare provider to establish that a patient received adequate care. ${ }^{3}$

Clinical audit is a quality improvement process that seeks to improve patient care and outcomes through systematic review of care against explicit standards/ criteria and the implementation of changes in practice if needed. ${ }^{4}$

The definition of clinical audit as per the National Institute of Clinical Excellence (NICE): “A quality improvement process that seeks to improve patient care \& outcomes through systematic review of care against explicit criteria and the implementation of change". ${ }^{\prime}$

\section{AIMS AND OBJECTIVES}

Medical audit of documentation of inpatient medical record in a multispecialty hospital.

- To assess whether the existing documentation procedure is in accordance with the policy established by the hospital.

- To identify the lacunae in the same and to propose some possible solutions.

\section{MATERIALS AND METHODS}

\section{Study Design}

Retrospective, descriptive study. 


\section{Study Area}

A 545 bed multispecialty hospital in medical ward, gynecology and obstetrics ward, surgical ward, ENT ward, eye ward, pediatric ward, skin ward, and psychiatry ward.

\section{Sample Size}

Systematic random sample of all inpatient medical records of last 12 months. Sample size was 320 case sheets, 40 from each department.

The following records were assessed for completeness of documentation: admission information (date of admission and serial number), demographics (age, sex, and patient number), history, examination, investigations, diagnosis, and treatment, attending doctor, procedures, summary-of-a-day, and follow-up. Other information checked to find out admission information: serial number and date of admission; demographics: age, sex, and hospital number; history: presence of documentation in correct section; examination: presence of documentation in correct section; investigations: presence of documentation in correct section; diagnosis: presence of documentation in correct section; treatment: presence of documentation in correct section; attending doctor: named doctor documented; procedures: procedures noted in correct section; summary-of-a-day: 1st, 2nd, and 3rd named doctor on-call. Follow-up was measured but excluded from the final primary outcome analysis as it is often completed at a different time to the rest of the inpatient book.

\section{Data Collection}

The data collected were primary and the source was the discharge case files of the last 12 months available in the medical record section. The approach used for data collection was quantitative. The techniques applied were survey and observation. A structured checklist (audit tool) was developed (Table 1) keeping few of the quality indicators as the benchmark.

Table 1: Checklist for clinical audit of medical records of inpatients

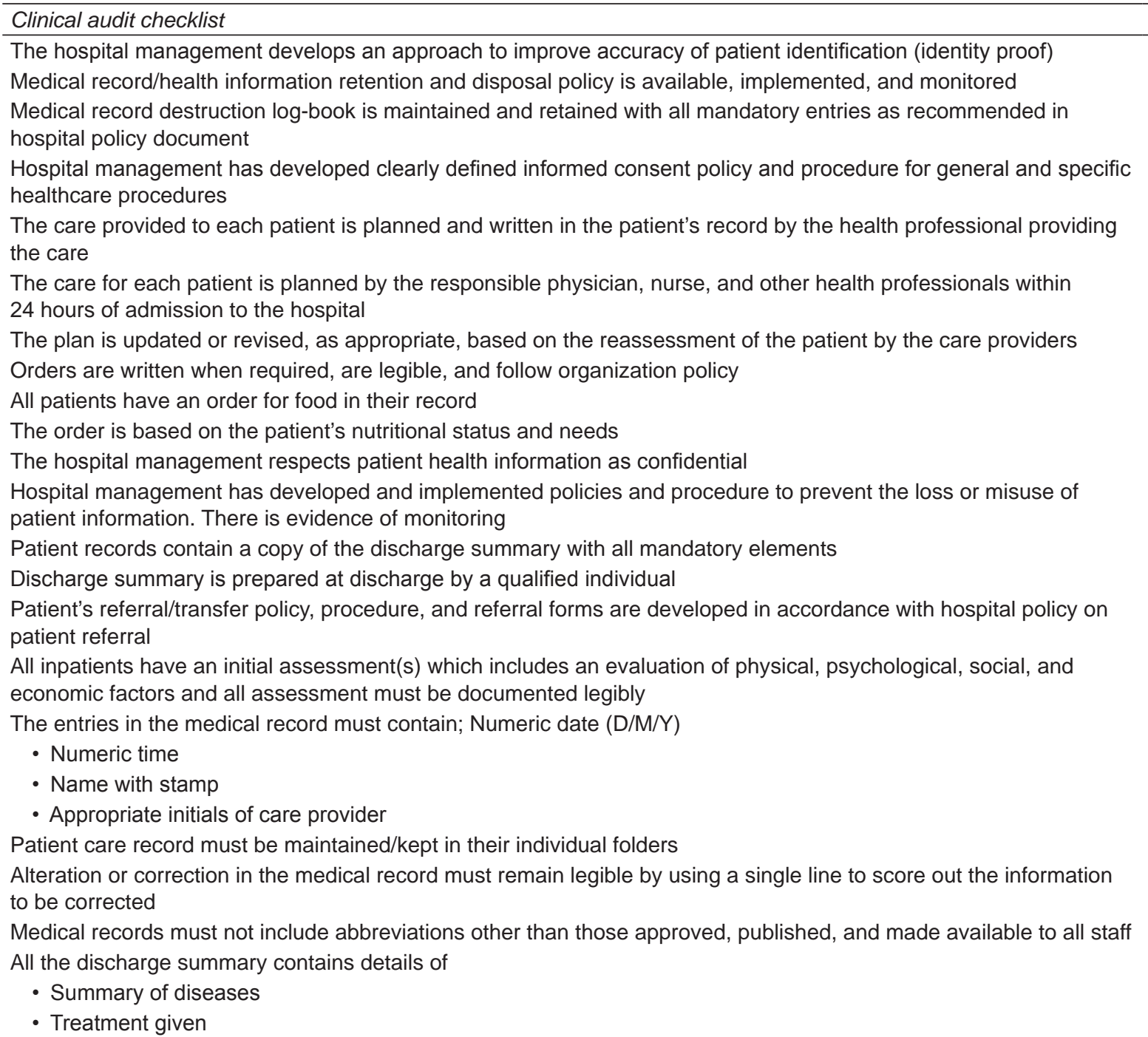

The hospital management develops an approach to improve accuracy of patient identification (identity proof)

Medical record/health information retention and disposal policy is available, implemented, and monitored hospital policy document healthcare procedures

the care

The care for each patient is planned by the responsible physician, nurse, and other health professionals within 24 hours of admission to the hospital Orders are written when required, are legible, and follow organization policy

All patients have an order for food in their record

The hospital management respects patient health information as confidential

Hospital management has developed and implemented policies and procedure to preve patient information. There is evidence of monitoring

Discharge summary is prepared at discharge by a qualified individual

Patient's referral/transfer policy, procedure, and referral forms are developed in accordance with hospit patient referral economic factors and all assessment must be documented legibly

The entries in the medical record must contain; Numeric date $(\mathrm{D} / \mathrm{M} / \mathrm{Y})$

Name with stamp

Alteration or correction in the medical record must remain legible by using a single line to score out the information to be corrected

All the discharge summary contains details of

- Treatment given 
(Cont'd...)

\begin{tabular}{lc}
\hline Clinical audit checklist & Yes \\
\hline - Follow-up instruction & No \\
- Instruction for patient & \\
Discharge summary contains ICD number \\
Discharge summary contains signature of treating physician/surgeon \\
MLC initiated in all cases where it should initiated \\
LAMA patients have given their unwillingness of treatment \\
Lab investigation form duly filled and entered in case sheet
\end{tabular}

ICD: International Classification of Diseases; MLC: Medicolegal case; LAMA: Leaving against medical advice

\section{OBSERVATIONS AND DISCUSSION}

There is clearly a large discrepancy between the standard of record keeping in various departments. Psychiatry department was found to be best while gynecology and pediatric departments were found not satisfactory. Planned care was not provided to the patients as per standard protocol in surgical and psychiatric wards as shown in Table 2. Almost all departments (5-10\%) were not documenting the food order in the medical records. Entry in medical record for date/name/sign was not present in most of the departments, notably in gynecology department $(25 \%)$. Leaving against medical advice (LAMA) patients were discharge without taking unwillingness for treatment certificate in pediatric $(10 \%)$ and gynecology department $(5 \%)$ patients. International Classification of Diseases number was not found in gynecology $(40 \%)$ and skin $(20 \%)$ patients' discharge. Discharge summary was not found duly completed in gynecology, eye, and pediatric wards $(20 \%)$. Alteration in medical records was found in almost all the departments.

Table 2: Various department-wise findings

\begin{tabular}{|c|c|c|c|c|c|c|c|c|}
\hline Clinical audit checklist & $\begin{array}{l}\text { Medical } \\
\text { ward (40) }\end{array}$ & $\begin{array}{l}\text { Gynecology } \\
\text { and } \\
\text { obstetrics } \\
\text { ward (40) }\end{array}$ & $\begin{array}{l}\text { Surgical } \\
\text { ward (40) }\end{array}$ & $\begin{array}{l}\text { ENT } \\
\text { ward } \\
(40)\end{array}$ & $\begin{array}{l}\text { Eye } \\
\text { ward } \\
(40)\end{array}$ & $\begin{array}{l}\text { Pediatric } \\
\text { ward (40) }\end{array}$ & $\begin{array}{l}\text { Skin } \\
\text { ward } \\
(40)\end{array}$ & $\begin{array}{l}\text { Psychiatr } \\
\text { ward (40) }\end{array}$ \\
\hline $\begin{array}{l}\text { The hospital management develops an } \\
\text { approach to improve accuracy of patient } \\
\text { identification (identity proof) }\end{array}$ & Yes & Yes & Yes & Yes & Yes & Yes & Yes & Yes \\
\hline $\begin{array}{l}\text { Medical record/health information } \\
\text { retention and disposal policy is available, } \\
\text { implemented, and monitored }\end{array}$ & Yes & Yes & Yes & Yes & Yes & Yes & Yes & Yes \\
\hline $\begin{array}{l}\text { Medical record destruction log-book is } \\
\text { maintained and retained with all mandatory } \\
\text { entries as recommended in hospital policy } \\
\text { document }\end{array}$ & Yes & Yes & Yes & Yes & Yes & Yes & Yes & Yes \\
\hline $\begin{array}{l}\text { Hospital management has developed } \\
\text { clearly defined informed consent policy and } \\
\text { procedure for general and specific healthcare } \\
\text { procedures }\end{array}$ & Yes & Yes & Yes & Yes & Yes & No & No & No \\
\hline \multirow{2}{*}{$\begin{array}{l}\text { The care provided to each patient is planned } \\
\text { and written in the patient's record by the health } \\
\text { professional providing the care (Graph } 1 \text { ) }\end{array}$} & Yes: 32 & Yes: 31 & Yes: 28 & Yes: 34 & Yes: 36 & Yes: 32 & Yes: 34 & Yes: 30 \\
\hline & No: 8 & No: 9 & No: 12 & No: 6 & No: 4 & No: 8 & No: 6 & No: 10 \\
\hline $\begin{array}{l}\text { The care for each patient is planned by the } \\
\text { responsible physician, nurse, and other } \\
\text { health professionals within } 24 \text { hours of } \\
\text { admission to the hospital }\end{array}$ & Yes & Yes & Yes & Yes & Yes & Yes & Yes & Yes \\
\hline \multirow{2}{*}{$\begin{array}{l}\text { The plan is updated or revised, as } \\
\text { appropriate, based on the reassessment of } \\
\text { the patient by the care providers (Graph 2) }\end{array}$} & Yes: 30 & Yes: 32 & Yes: 30 & Yes: 32 & Yes: 30 & Yes: 32 & Yes: 36 & Yes: 38 \\
\hline & No: 10 & No: 8 & No: 10 & No: 8 & No: 10 & No: 8 & No: 4 & No: 2 \\
\hline $\begin{array}{l}\text { Orders are written when required, are legible, } \\
\text { and follow organization policy }\end{array}$ & Yes & Yes & Yes & Yes & Yes & Yes & Yes & Yes \\
\hline \multirow{2}{*}{$\begin{array}{l}\text { All patients have an order for food in their } \\
\text { record (Graph 3) }\end{array}$} & Yes: 31 & Yes: 30 & Yes: 34 & Yes: 30 & Yes: 32 & Yes: 32 & Yes: 32 & Yes: 30 \\
\hline & No: 9 & No: 10 & No: 6 & No: 10 & No: 8 & No: 8 & No: 8 & No: 10 \\
\hline \multirow{2}{*}{$\begin{array}{l}\text { The order is based on the patient's nutritional } \\
\text { status and needs }\end{array}$} & Yes: 31 & Yes: 30 & Yes: 34 & Yes: 30 & Yes: 32 & Yes: 32 & Yes: 32 & Yes: 30 \\
\hline & No: 9 & No: 10 & No: 6 & No: 10 & No: 8 & No: 8 & No: 8 & No: 10 \\
\hline
\end{tabular}

(Cont'd...) 
(Cont'd...)

\begin{tabular}{|c|c|c|c|c|c|c|c|c|}
\hline Clinical audit checklist & $\begin{array}{l}\text { Medical } \\
\text { ward (40) }\end{array}$ & $\begin{array}{l}\text { Gynecology } \\
\text { and } \\
\text { obstetrics } \\
\text { ward (40) }\end{array}$ & $\begin{array}{l}\text { Surgical } \\
\text { ward (40) }\end{array}$ & $\begin{array}{l}\text { ENT } \\
\text { ward } \\
\text { (40) }\end{array}$ & $\begin{array}{l}\text { Eye } \\
\text { ward } \\
\text { (40) }\end{array}$ & $\begin{array}{l}\text { Pediatric } \\
\text { ward (40) }\end{array}$ & $\begin{array}{l}\text { Skin } \\
\text { ward } \\
\text { (40) }\end{array}$ & $\begin{array}{l}\text { Psychiatry } \\
\text { ward (40) }\end{array}$ \\
\hline $\begin{array}{l}\text { The hospital management respects patient } \\
\text { health information as confidential }\end{array}$ & Yes & Yes & Yes & Yes & Yes & Yes & Yes & Yes \\
\hline $\begin{array}{l}\text { Hospital management has developed } \\
\text { and implemented policies and procedure } \\
\text { to prevent the loss or misuse of patient } \\
\text { information. Evidence of monitoring }\end{array}$ & Yes & Yes & Yes & Yes & Yes & Yes & Yes & Yes \\
\hline $\begin{array}{l}\text { Patient records contain a copy of the discharge } \\
\text { summary with all mandatory elements }\end{array}$ & Yes & Yes & Yes & Yes & Yes & Yes & Yes & Yes \\
\hline $\begin{array}{l}\text { Discharge summary is prepared at discharge } \\
\text { by a qualified individual }\end{array}$ & Yes & Yes & Yes & Yes & Yes & Yes & Yes & Yes \\
\hline $\begin{array}{l}\text { Patient's referral/transfer policy, procedure, and } \\
\text { referral forms are developed in accordance } \\
\text { with hospital policy on patient referral }\end{array}$ & Yes & Yes & Yes & Yes & Yes & Yes & Yes & Yes \\
\hline All inpatients have an initial assessment(s) & Yes & Yes & Yes & Yes & Yes & Yes & Yes & Yes \\
\hline
\end{tabular}
which includes an evaluation of physical, psychological, social, and economic factors and all assessment must be documented legibly

The entries in the medical record must contain numeric date $(D / M / Y)$
Yes: 32 Yes: 30

No: 8 No: 10
Yes: 32 Yes: 34 Yes: 32 Yes: 34

Yes: 36 Yes: 34

- Numeric time

- Name with stamp

- Appropriate initials of care provider (Graph 4)

Patient care record must be maintained/kept in their individual folders (Graph 5)

Alteration or correction in the medical record must remain legible by using a single line to score out the information to be corrected (Graph 6)

Medical records must not include

abbreviations other than those approved,

published, and made available to all staff

All the discharge summary contains details of

No: $8 \quad$ No: 10

- Summary of diseases

- Treatment given

- Follow-up instruction

- Instruction for patients (Graph 7)

Discharge summary contains ICD number (Graph 8)

Discharge summary contains signature of treating physician/surgeon

MLC initiated in all cases where it should be Yes initiated

LAMA patients have given their unwillingness Yes of treatment (Graph 9)

Yes: 34 Yes: 36

No: 6 No: 4

Yes: 32 Yes: 32

No: $8 \quad$ No: 8

Yes Yes

No: 6

No: 8

No: 6

No: 4 No: 6
Yes: 36 Yes: 34 Yes: 32 Yes: 32

Yes: 34 Yes: 34

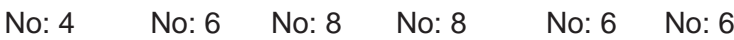

Yes: 34 Yes: 34 Yes: 32 Yes: 32

Yes: 38 Yes: 34

No: 6

No: 6 No: 8 No: 8

No: 2 No: 6

Yes: $34 \quad$ Yes: 36 Yes: 32 Yes: 32 Yes: 36 Yes: 34

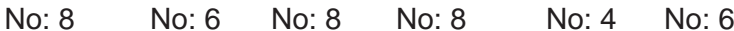

Yes: 34 Yes: 36 Yes: 36 Yes: 38 Yes: 32 Yes: 38

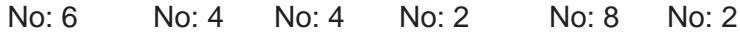

Yes Yes Yes Yes Yes Yes

Yes Yes Yes Yes Yes Yes

Yes Yes Yes Yes Yes Yes

No: 4

Yes: 36 Yes: 36 Yes: $34 \quad$ Yes: 38 Yes: 34 Yes: 38

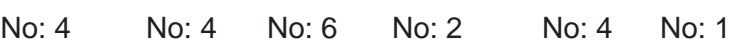

Lab investigation form duly filled and entered Yes: 38

Yes: 36 Yes: 34

No: 4 No: 16

Yes

Yes

Yes

Yes

No: 2

Yes: 32

No: 2

No: 8

in case sheet (Graph 10)

ICD: International classification of diseases; MLC: Medicolegal case; LAMA: Leaving against medical advice 


\section{RECOMMENDATIONS}

- Root cause analysis to be done to find out the reason for lapse in certain departments.

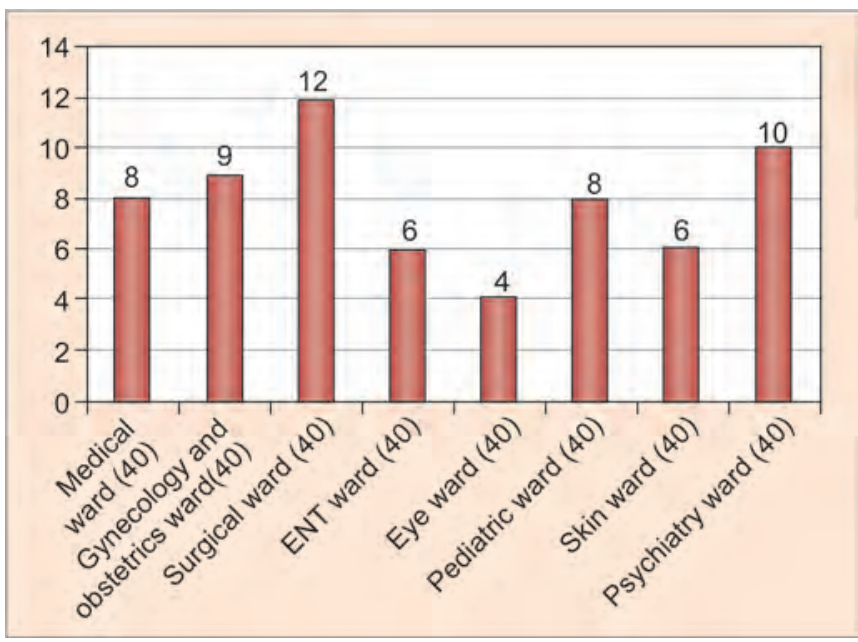

Graph 1: Planned care not provided to patient as per standard protocol
- Sensitizing the clinical and clerical staff regarding the importance of correct record keeping should be stressed to the interns both from a patient care and research perspective. ${ }^{6}$

- Hospital-wide standardization of the medical record keeping including admission and discharge summary. ${ }^{7}$

- Rewarding the best performing department/unit and educating and training the responsible staff to make a complete record of every patient should be emphasized in hospital.

- There should be quarterly medical audit of the documentation procedure.

- The interns/residents responsible for filling in the inpatient records should be taught how to adequately fill in the records in a scientific manner. ${ }^{8}$

- A weekly check of the medical records by consultant to assure that it is being completed.

- In addition, sections in the pro forma should be filled in according to their title, to maintain clarity of notes. ${ }^{9}$

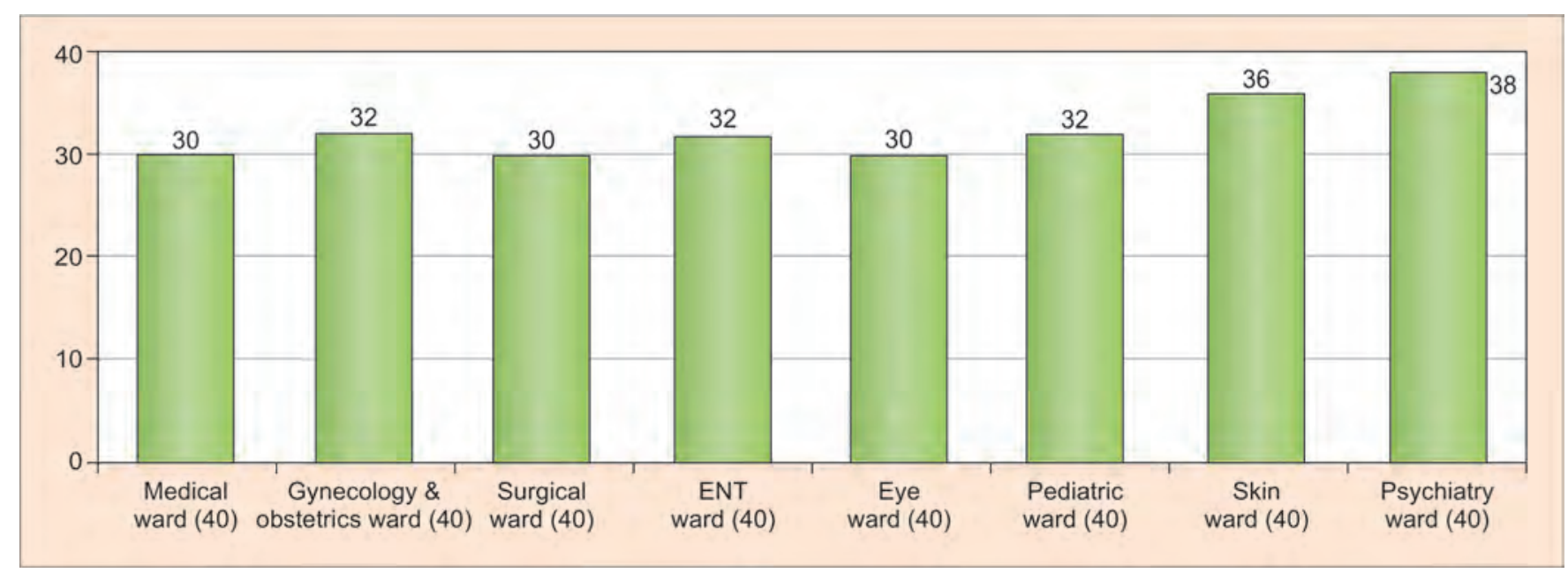

Graph 2: Updated or revised plan, as appropriate, based on the reassessment of the patient by the care providers

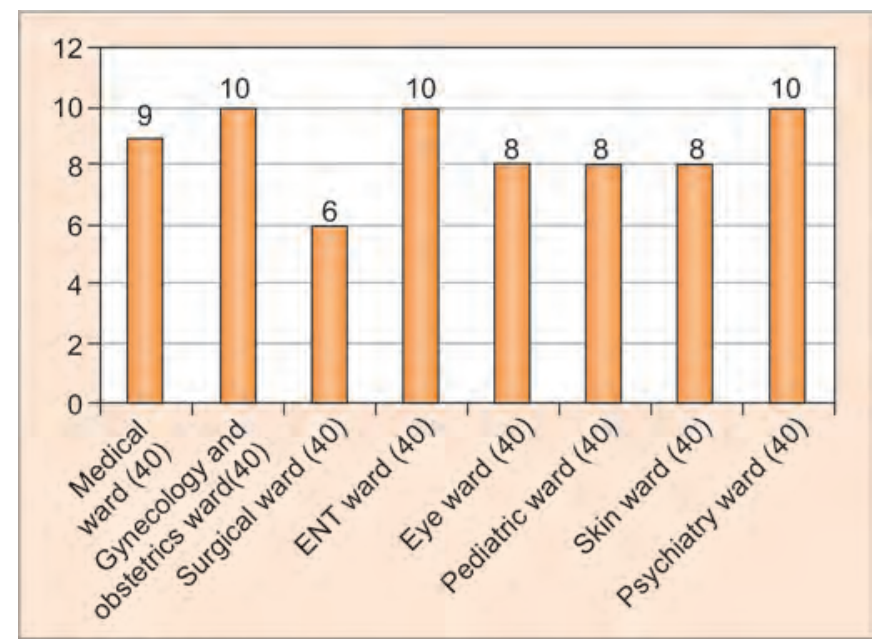

Graph 3: Nondocumentation of food order in medical record

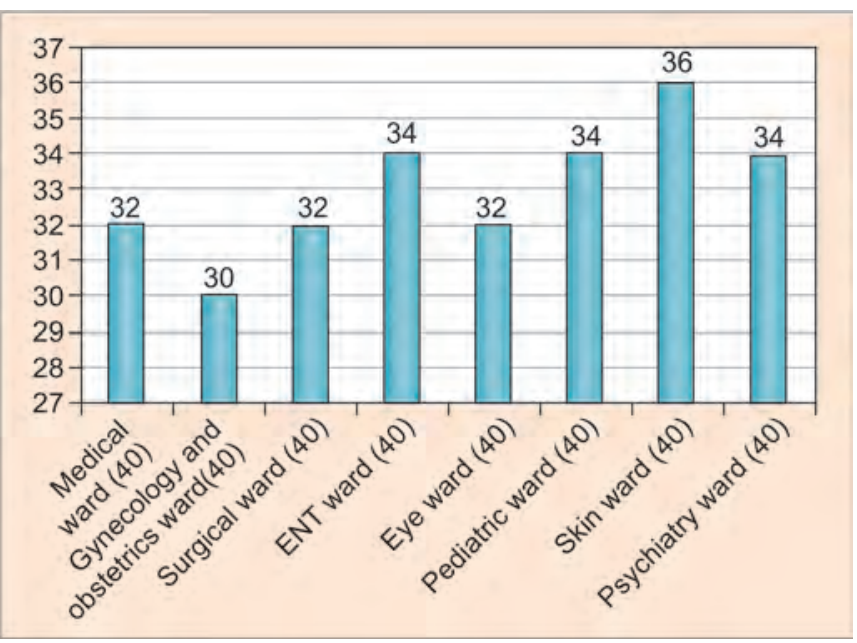

Graph 4: Entry in medical record for date/name/sign 


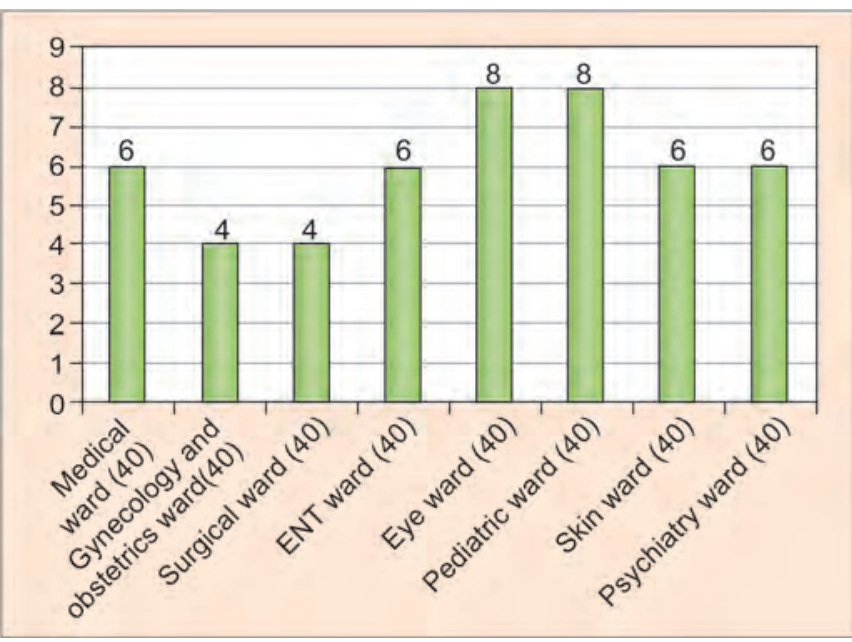

Graph 5: Patient care record not maintained/kept in their individual folders

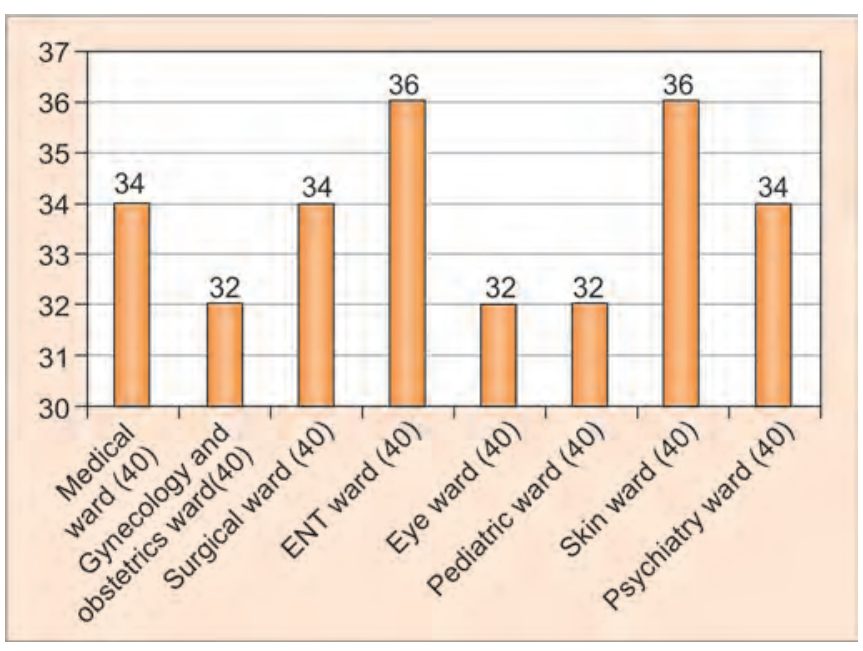

Graph 7: Completion of discharge summary

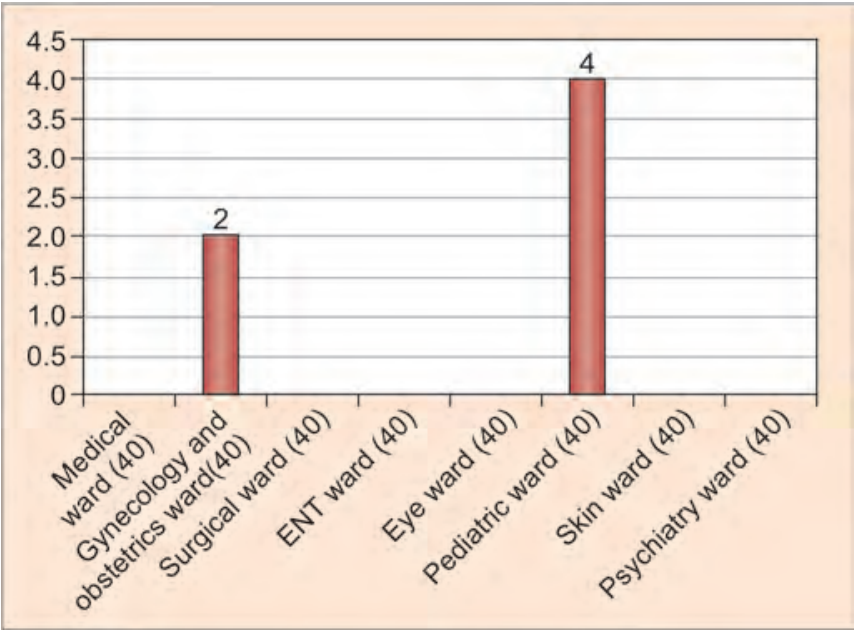

Graph 9: Leaving against medical advice patients have not given their unwillingness of treatment

- It should be the responsibility of the discharging doctor or ward in charge to return to the inpatient records and complete the required section on "follow-up". This should also be signed by the respective physician. ${ }^{10}$

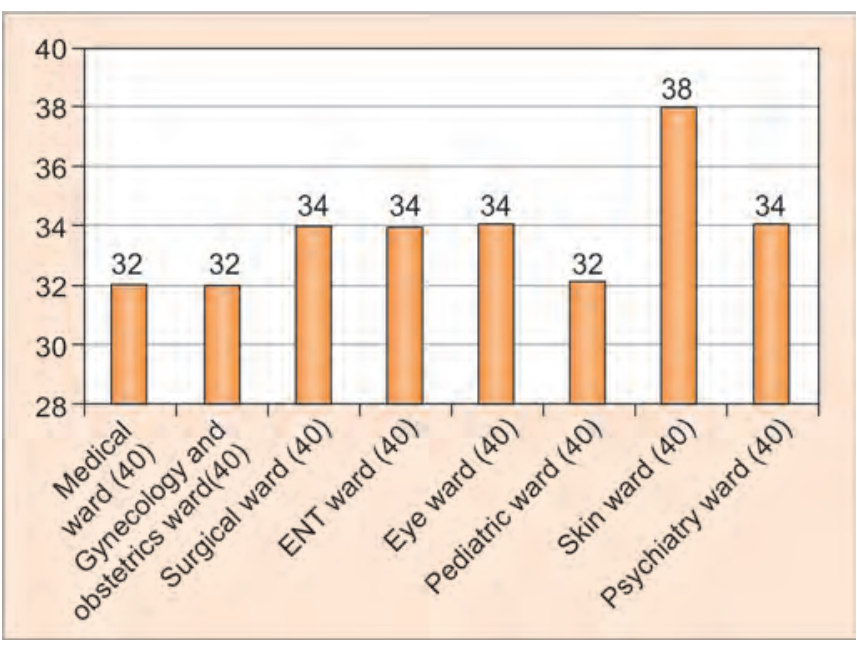

Graph 6: Alteration or correction in the medical record

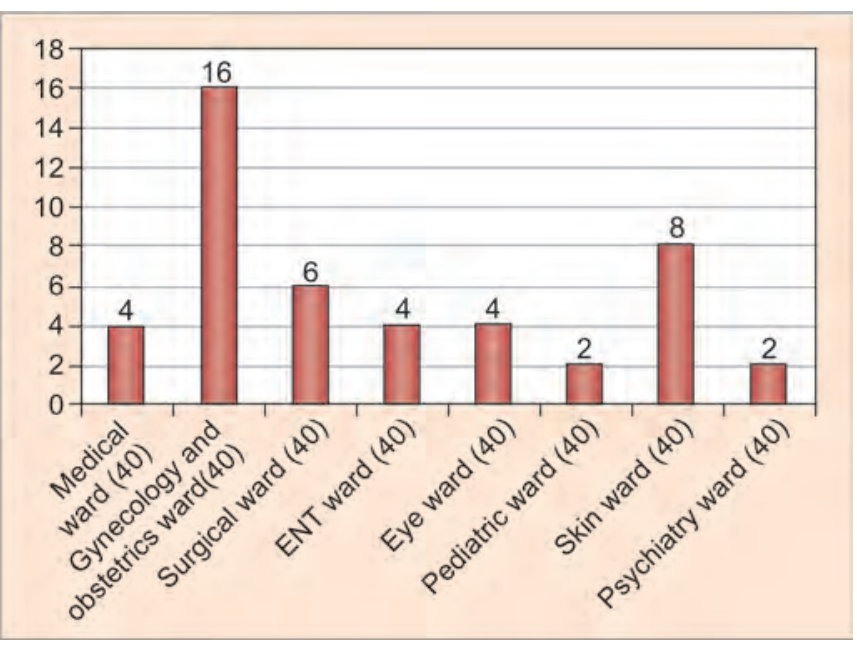

Graph 8: International Classification of Diseases number not entered in discharge summary

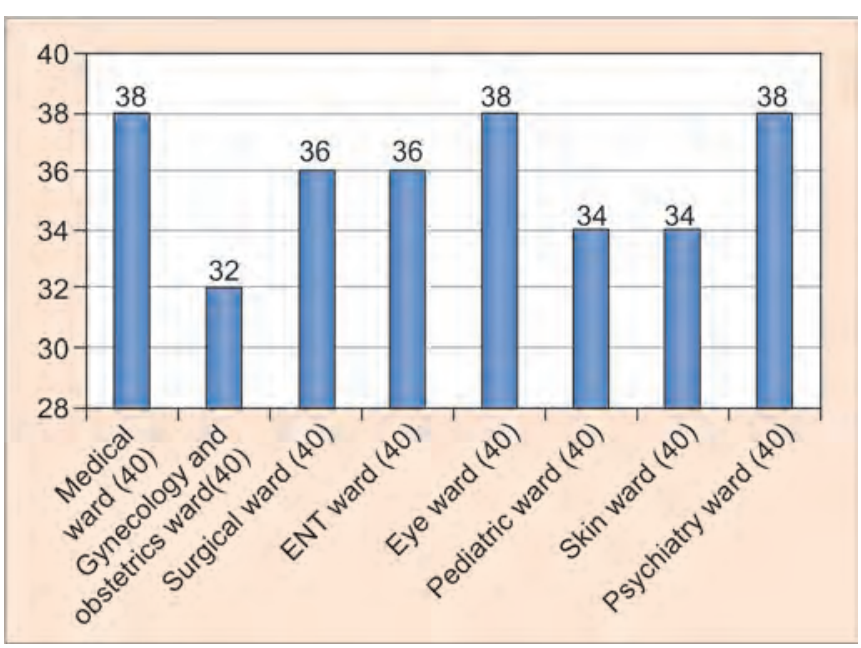

Graph 10: Lab investigation form duly filled and entered in case sheet

\section{CONCLUSION}

Medical records are technically valid health records which must provide an overall correct description of each patient's details of care or contact with hospital personnel. 
Medical records form a very important and critical document in hospital. These records are vital for legal purposes and for future planning of the hospital medical care. All possible steps should be taken to ensure that all hospital medical records are maintained in systemic and orderly manner. The importance of the medical records should also be communicated to all staff. Periodic audits of the medical records will help to determine the possible deficiency in keeping records, which can be improved and worked upon by the hospital.

\section{REFERENCES}

1. Chamisa I, Zulu BM. Setting the records straight: a prospective audit of the quality of case notes in a surgical department. S Afr J Surg 2007 Aug;45(3):92, 94-95.

2. Desalu I, Olanipekun O, Agbamu P. An audit of anaesthesia record keeping at the Lagos University Teaching Hospital. Afr J Anaesth Int Care 2010 Oct;10(1):1-5.

3. Dosumo EB, Dosumo OO, Lawal FB. Quality of records keeping undergraduate dental students in Ibadan, Nigéria. Ann Ib Postgrad Med 2012 Jun;10(1):13-17.
4. Kediegile G, Madzimbamuto FD. Obstacles faced when conducting a clinical audit in Botswana. South Afr J Anaesth Analg 2014;20(2):127-131.

5. Maegga BT, Cox J, Malley KD. Malaria in the southern highlands of Tanzania: a review of hospital records. Tanzan Health Res Bull 2005 Sep;7(3):125-132.

6. Omigbodun AO. Improving standards in practice through medical audit. Ann Ib Postgrad Med 2004 Jun;1(2):23-26.

7. Poscia A, Cambieri A, Tucceri C, Ricciardi W, Volpe M. Audit as a tool to assess and promote the quality of medical records and hospital appropriateness: metodology and preliminary results. Ig Sanita Pubbl 2015 Mar-Apr;71(2):139-156.

8. Robertson AR, Fernando B, Morrison Z, Kalra D, Sheikh A. Structuring and coding in health care records: a qualitative analysis using diabetes as a case study. J Innov Health Inform 2015 Mar;22(2):275-283.

9. Walker RW, Viney R, Green L, Mawanswila M, Maro VP, Gjertsen C, Godfrey H, Smailes R, Gray WK. Trends in stroke admissions to a Tanzanian hospital over four decades: a retrospective audit. Trop Med Int Health 2015 Oct;20(10): 1290-1296.

10. Weed LL. Medical records that guide and teach. N Engl J Med 1968 Mar;278(11):593-600. 